\title{
The Use of Antidepressant Drugs and the Lifetime Prevalence of Major Depressive Disorders in Italy
}

\author{
Mauro Giovanni Carta ${ }^{* \dagger}$, Eugenio Aguglia ${ }^{* *}$, Alberto Bocchetta $^{\dagger}$, Matteo Balestrieri ${ }^{* * *}$, Filippo \\ Caraci $^{* *}$, Massimo Casacchia , Liliana Dell’Osso , Guido Di Sciascio ${ }^{\circ}$, Filippo Drago ${ }^{* *}$, Carlo \\ Faravelli $^{\#}$, Maria Efisia Lecca ${ }^{\dagger}$, Maria Francesca Moro ${ }^{\dagger}$, Pier Luigi Morosini ${ }^{\#}$, Marcello Nardini ${ }^{\circ}$, \\ Gabriella Palumbo ${ }^{\# \#}$ and Maria Carolina Hardoy ${ }^{\dagger}$
}

\author{
${ }^{\dagger}$ University of Cagliari; **University of Catania; ***University of Udine; ${ }^{\circ}$ University of L 'Aquila; ${ }^{\circ}$ University of \\ Pisa; ${ }^{\circ 0}$ University of Bari; ${ }^{\#}$ University of Florence; ${ }^{\# \#}$ National Institute of Health, Rome
}

\begin{abstract}
:
Background: The increased use of antidepressant drugs (ADs) improved the response to the needs of care although some community surveys have shown that subjects without lifetime psychiatric diagnosis (anxiety/depression) used ADs.

Objectives: To evaluate the appropriateness and amount of prescription of psychotropic drugs in people with lifetime diagnosis of Major Depressive Disorder (MDD) by means of community survey with a semi-structured interview as a diagnostic instrument, administered by clinicians.

Methods: Study design: community survey.

Study population: samples randomly drawn, after stratification from the adult population of municipal records. Sample size: 4.999 people were drawn in 7 centres of 6 Italian regions.

Tools: questionnaire on psychotropic drug consumption, prescription, health services utilization; Structured Clinical Interview for DSM-IV modified (ANTAS); Training: interviewers were trained psychologists or medical doctors.

Results: 3.398 subjects were interviewed (68\% of the recruited sample). The lifetime prevalence of DSM-IV MDD was $4.3 \%$ in males and $11.5 \%$ in females; antidepressant drugs were taken by $4.7 \%$ of subjects, $2.9 \%$ male and $5.9 \%$ female. $38 \%$ of males and $57 \%$ of females with lifetime diagnosis of MDD were taking ADs.

Conclusions: Compared with studies using lay interviewers and structured tools the prevalence of the MDD was quite lower; ADs use was higher and tallied well with the data regarding antidepressant sales in Italy; the correspondence between lifetime diagnosis of MDD and ADs use was closer.
\end{abstract}

Keywords: Antidepressant drugs, major depressive disorders, bipolar disorders, community survey, lifetime prevalence.

\section{INTRODUCTION}

Direct expenditure for ADs in Italy incremented at a $25 \%$ rate from 2000 to 2002 [1]. A number of population surveys have shown that the ADs usage increase is associated with an improved response to patients' needs of those diagnosed with depression. However, the appropriateness of ADs prescription is still open to debate. For more than a decade (1991 to 2002), in a community repeated survey performed in the Italian region of Sardinia, the number of individuals with a defined diagnosis of depression while taking ADs, increased from $8 \%$ to $40 \%$ [2]. The proportion of adults in the community who took antidepressants was $4.2 \%$ in 2002. However, $60 \%$ of subjects diagnosed with Depressive Episode (X International Classification of Diseases [ICD-10], [3]) did not have proper pharmacological treatment. On the other hand, a relevant proportion of subjects without lifetime

*Address correspondence to this author at the Department of Public Health, University of Cagliari, Italy; Tel: +39 335 499994; Fax: +39 070496294; E-mail: mgcarta@ tiscali.it psychiatric diagnosis (anxiety and/or depression) used antidepressants. Pharmacologic therapy was managed by psychiatrists in $44.2 \%$ of cases, but ADs were prescribed by general practitioners (GPs) in $31.8 \%$ of cases [2].

It has been hypothesised that a relevant proportion of ADs prescriptions was addressed to treat subsyndromal disorders. In primary care, physicians label anxiety and affective disorders as clinical conditions that do not meet Diagnostic Statistical Manual (DSM) IV [4] definitional thresholds for axis I anxiety or mood disorders [5]. Subsyndromal depression and anxiety are clinically relevant and of importance in public health because of pervasive impairment of psychosocial functions, a high rate of medical co-morbidity and a high rate of service utilization. Controversially, there is a lack of agreement about the use of antidepressants in subsyndromal depression and evidence from clinical trials is scarce. A non-replicated study of Paykel [6] found that antidepressants were no more efficacious than placebo in patients with subsyndromal depression. More recently, Rocca et al. [7] found that the antidepressants sertraline and citalo- 
pram can improve depressive symptoms and cognitive functions of minor depressive disorders and subsyndromal depressive symptomatology in elderly and non demented patients in a 1 year non-randomized follow-up clinical trial. On the contrary, a large number of researches found the efficacy in counseling and psychosocial therapies [8].

\section{STUDY OBJECTIVES}

The general study objective is to evaluate the appropriateness and amount of over and under-psychotropic drug prescription in different Italian areas, with a special focus on the general use of antidepressants.

As for a diagnostic instrument, we use a tool derivate from defined and validated international semi-structured interviews that are administered by expert clinicians.

In this first report we present the data among the lifetime prevalence of major depressive disorders. This also includes the prevalence of anti-depressant drug use in the sites of the research and the appropriateness of the AD prescriptions against the clinical diagnosis.

\section{METHODS}

\section{Design}

The proposed study design is a community survey.

Face to face interviews were carried out at candidates' homes.

\section{Recruitment Methods and Study Sample}

Study sample was randomly drawn from the adult population of municipal records in seven different areas including different Italian locations with wide variations in socioeconomic conditions and prescriptive patterns. This included: Sicily (Catania), Sardinia (Sulcis), Puglia (Bari) in the South, Tuscany (Florence and Pisa) and Abruzzo (L'Aquila) in central Italy and Friuli-Venezia Giulia (Udine) in northern Italy. In each area, both an urban and a rural subarea were selected. The urban subareas were Iglesias in Sulcis (Sardinia), Catania in Sicily, Bari in Puglia, Pisa in Tuscany and Udine in Friuli-Venezia Giulia. A third of the sample in each centre was drawn from 3 variously populated municipalities; less than 2.000 , from to 2.001 to 10.000 in-habitants and from 10.001 to 20.000 inhabitants. They were also randomly drawn from the municipalities of the same province not bordering the urban area.

The sample of Udine was only urban and Florence was only rural.

Randomisation was performed after stratification by sex and four different age groups (18-24; 25-44; 45-64; >64).

Using the above mentioned methodology, a sample of 4.999 people was drawn from the 7 centres. The size of the sub drawn samples were: 704 in L'Aquila; 971 in Bari; 666 in Catania; 846 in Florence; 465 in Sulcis; 464 in Pisa and 882 in Udine.

Included in each person's sample was their general practitioner's name which was obtained from the general practitioner's health authority registry (practically each Italian resident is registered with a GP). The relevant general practi- tioners were asked to sign an invitation to their patients for survey collaboration.

Subjects were contacted and interviewed at home by the local coordinator of the study.

\section{Interview, Tools and Study Assessment}

Interviews consist of the following tools:

1. Ad hoc form to assess basic demographic data

2. a questionnaire on psychotropic drug consumption, prescription circumstances and health services utilization [3];

3. the "Advanced Neuropsychiatric Tools and Assessment Schedule" (ANTAS) a semi-Structured Clinical Inter-view derived in part from the non patient version (SCIDI/NP) for DSM-IV [9] to assess the presence of full or sub-threshold psychiatric disorders (this, as already said, requires a clinical competence to be administered as planned in the study protocol). A reliability study of the diagnosis derived for the ANTAS against SCID was preliminarily carried out and the results were previously published [10]. The reliability concerning mood and anxiety diagnosis with SCID was measured with a mean $\mathrm{K}$ of 0.85 [10].

Interviewers asked the interviewees to show them their drug boxes and were provided with a folder to retain all of the psychotropic drug box covers.

For all the subjects' were ascertained antidepressant drugs consumption (tricyclics, SSRI, SNRI and NARI), as positive at use were identified subjects assuming antidepressants drugs at therapeutic dosages for every day at least the 15 days before the interview.

\section{Interviewers and Training}

Interviewers were selected from psychologists and medical doctors with at least two years experience of clinical psychiatric work after graduation.

They received common intensive training in the use of the research instrument and administration of home interviews.

Intensive training was carried out by the Coordination Unit.

Interviewers were provided with a laptop computer and hoc software to immediately record data.

Two assistant researchers from the Coordinating Unit travelled to each field unit, interviewed at least 7 patients and three normal control subjects that were then re-interviewed by the local interviewers. Differences in results were discussed and sorted out. The diagnosis reliability between coordinator centre researchers and each other unit had an average higher than $\mathrm{K}>80$.

\section{Monitoring and Quality Control}

Interview quality was monitored by cross examining the interviewers every three months and having at least 120 interviews that were repeated by different interviewers. This task was then carried out by the "Associazione Università Europea del Mediterraneo" in collaboration with the coordinator centre. 
Table 1. Enrolled Sample by Centre, Sex and Rate of the Non-interviewed (Deceased, Uncontacted, Transferred or Refusal)

\begin{tabular}{|c|c|c|c|c|c|c|}
\hline Centre & $\begin{array}{c}\text { Interviewed } \\
\text { Males }\end{array}$ & $\begin{array}{c}\text { Interviewed } \\
\text { Females }\end{array}$ & Total Interviewed & $\begin{array}{c}\text { Non } \\
\text { Interviewed }\end{array}$ & $\begin{array}{l}\text { Total Sample } \\
\text { Randomized }\end{array}$ & $\begin{array}{c}\% \text { of Non- } \\
\text { Interviewed }\end{array}$ \\
\hline L'Aquila & 253 & 300 & 553 & 151 & 704 & 21.4 \\
\hline Bari & 384 & 421 & 805 & 167 & 972 & 17.2 \\
\hline Catania & 210 & 294 & 504 & 162 & 666 & 24.3 \\
\hline Florence & 266 & 422 & 688 & 158 & 846 & 18.9 \\
\hline Sulcis (Sardinia) & 108 & 198 & 306 & 159 & 465 & 34.1 \\
\hline Pisa & 60 & 94 & 154 & 310 & 464 & 66.8 \\
\hline Udine & 156 & 232 & 388 & 494 & 882 & 56.0 \\
\hline Total & 1437 & 1961 & 3398 & 1601 & 4999 & 32.0 \\
\hline
\end{tabular}

Table 2. Enrolled Sample Characteristics by Age, Sex and the Non-Interviewed Rate

\begin{tabular}{|c|c|c|c|c|c|c|c|c|}
\hline Age & $\begin{array}{c}\text { Interviewed } \\
\text { Males }\end{array}$ & \% of Total & $\begin{array}{c}\text { Non- } \\
\text { Interviewed }\end{array}$ & $\begin{array}{c}\text { \% of Non- } \\
\text { Interviewed }\end{array}$ & $\begin{array}{c}\text { Interviewed } \\
\text { Females }\end{array}$ & $\begin{array}{c}\text { Non- of Total } \\
\text { Interviewed } \\
\text { Females }\end{array}$ & $\begin{array}{c}\text { \% of Non- } \\
\text { Interviewed }\end{array}$ \\
\hline \hline $18-24$ & 192 & 14 & 180 & 48 & 241 & 12 & 97 & 29 \\
\hline $25-44$ & 499 & 35 & 378 & 44 & 614 & 31 & 226 \\
\hline $45-64$ & 460 & 31 & 287 & 39 & 707 & 37 & 242 \\
\hline$>64$ & 286 & 20 & 140 & 33 & 399 & 1952 & 100 & 645 \\
\hline Total & $1437 *$ & 100 & 985 & 41 & 26 & 25 \\
\hline
\end{tabular}

Data checks and editing were periodically accomplished and input software assured that the easiest checks were done automatically.

\section{Data Collection}

Data collection and the modalities for databank creation may be checked directly on the official research site (http://www.mooditaly.com/) with an appropriate password. The site was used to load peripheral centres data to the databank and for monitoring. Data was not nominal at source and each subject is identifiable with a code number.

\section{Statistical Considerations}

Statistical analysis templates were developed well before the data collection conclusion. Basic univariate and multivariate analyses were planned with $95 \%$ confidence limits.

\section{Sample Size}

It was envisaged that from $60 \%$ to $65 \%$ of the original sample (4.800 planned sample, 800 interviews from 6 centres) members may take part in the survey $(5 \%$ of members were expected to be deceased or moved, $10 \%$ were expected to be non retrievable and $20 \%$ were considered the refusal rate) for an expected total about 3.000 interviewed people. This sample size was expected to provide a $95 \%$ confidence interval of $+0.036 \%$ of the expected prevalence summary estimate of $4 \%$ of both antidepressant consumption and bipo- lar disorders as MDQ positives (relative standard error being around $7 \%$ ).

The final sample of 4.999 subjects from 7 centres will be explained in the results section and the proportion that took part in the study was $68 \%$ which was nearly the expected $60-$ $65 \%$.

\section{Ethical Aspects}

A signed informed consent for each candidate. The study was approved by the ethical committee of the Italian National Health Institute (Rome).

\section{RESULTS}

Table 1 summarizes the characteristics of the enrolled sample by centre, sex and rate of the non-interviewed (deceased, uncontacted, transferred or refusal). Sub-sample size per centre varies from 464 in Pisa to 972 in Bari. The highest non-interviewed rate was in Pisa $(66.8 \%)$ the lowest was in Bari (17.1).

Table 2 summarizes the characteristics of the enrolled sample by age, sex and the rate of non-interviewed. The male percentage of the non-interviewed was higher than the female ( $41 \%$ versus $25 \%$ ). The best adhesion rate was in the older age group for both for males and females.

For measuring the comparison between interviewed and randomized sub samples, reports are in 2X2 tables, for each of the 8 , by age/sex. Each table consists of 4 cells: 
Table 3. Comparison Between Interviewed and Randomized Sub Samples

\begin{tabular}{|c|c|c|c|c|}
\hline Age and Sex & Interviewed & Randomized & 2 (1DF) & P \\
\hline \hline Male 18-24 & 192 & 372 & 0.6 & 0.10 \\
\hline Male 25-44 & 498 & 876 & 0.1 & 0.42 \\
\hline Male 45-64 & 441 & 728 & 3.2 & 0.09 \\
\hline Male >64 & 286 & 426 & 0.39 & 0.53 \\
\hline Female 18-24 & 241 & 338 & 0.45 & 0.51 \\
\hline Female 24-44 & 609 & 835 & 0.005 & 0.81 \\
\hline Female 45-64 & 703 & 945 & 2.3 & 0.12 \\
\hline Female $>65$ & 399 & 479 & \\
\hline
\end{tabular}

Table 4. Lifetime Prevalence of MDD by Centre and Sex

\begin{tabular}{|c|c|c|c|c|}
\hline Centre & Male Sample & \% of MDD & $\begin{array}{l}\text { Female } \\
\text { Sample }\end{array}$ & \% of MDD \\
\hline \hline L'Aquila & 253 & 3.9 & 300 & 11.0 \\
\hline Bari & 384 & 2.9 & 421 & 5.2 \\
\hline Catania & 210 & 5.2 & 294 & 10.2 \\
\hline Florence & 266 & 5.6 & 198 & 21.2 \\
\hline Sulcis (Sar) & 108 & 10.0 & 94 & 20.2 \\
\hline Pisa & 60 & 5.1 & 232 & 14.2 \\
\hline Udine & 156 & 4.3 & 1961 & 11.5 \\
\hline Total & 1437 & & \\
\hline
\end{tabular}

Comparison with centres ( 2 with $6 \mathrm{DF}$ and Bonferroni correction): Male $2=9.96 \mathrm{P}^{=} 0.126$; female $2^{=} 48.2 \mathrm{P}<0.001$.

Cell a: interviewed per sex and age (e.g. male 18-24) Cell b: randomized by the same sex and age group,

Cell c: interviewed for all the others grouped by sex (e.g. male > 24).

Cell d: randomized sample for all other groups.

We calculate the 2, with 1 DF measuring in the cell, with the probability that the interviewed sample may differ from the randomized sample. Results are summarized in Table 3.

No significant statistical difference was found between the interviewed sub-samples and randomised sub-samples. The greatest difference was in the older age groups due to the better adhesion rate of both for male and female samples in these groups.

Table 4 shows the MDD lifetime prevalence by centre and sex. The prevalence in females was confirmed higher than in men $(11.5 \%$ versus $4.3 \%$ in the overall sample $2=47.5$ with $1 \mathrm{DF} \mathrm{P}=0.0001$ Odds Ratio 2.6 ), the overall rate in the sample was $8.5 \%$.

In the centres, the point prevalence varies in males from 1.8 (Sulcis) to $10.0 \%$ (Pisa) and in females from 5.2 (Florence) to 21.2 (Sulcis). Differences were without statistical significance in men (Comparison with centres, 2 with 6DF and Bonferroni correction, $2=9.96, \mathrm{P}=0.12)$ but reached statistical significance in females (Comparison with centres, 2 with 6DF and Bonferroni correction, 2=48.3, $\mathrm{P}<0.0001$ ).

Table 5 indicates the lifetime prevalence of MDD per age and sex.

Table 6 indicates the statistical differences in lifetime prevalence of MDD as per age and sex. Males had the highest prevalence in older age groups $(7.3 \%)$ but the difference with age 18-24 (used as pilot) didn't become of statistical significance. In women the age at risk was 45-64 with $13 \%$ of lifetime prevalence (OR versus 18-24 was 1.9, $21 \mathrm{df}$ $=4.8, \mathrm{P}<0.05)$.

Table 7 shows the use of antidepressants in the 7 communities. The use is indicated as positive if the subjects took antidepressants: in the last 15 days, almost every day or at least one antidepressant among tricyclics, SSRI, SNRI or NARI at therapeutic dosages. The usage in the total sample was $4.7 \%, 2.9 \%$ in males and 5.9\% in females (OR=1.9, 2 with $1 d f=12.0 P<0.0001)$. Comparison between centres reached statistical significance both in men and females, (2 with $6 \mathrm{DF}$ and Bonferroni correction) men $2=35.6, \mathrm{P}<0.0001$; females $2=29.9, \mathrm{P}<0.0001$. In men the centre with lowest use was Catania $(0 \%)$ and highest was Florence $(7.5 \%)$, in fe- 
Table 5. Lifetime Prevalence of MDD by Age and Sex

\begin{tabular}{|c|c|c|c|c|c|c|}
\hline Age & Male Sample & $\mathbf{N}^{\circ}$ of MDD & $\%$ & $\begin{array}{l}\text { Female } \\
\text { Sample }\end{array}$ & $\mathbf{N}^{\circ}$ of MDD & $\%$ \\
\hline $18-24$ & 192 & 6 & 3.1 & 241 & 16 & 6.6 \\
\hline $25-44$ & 499 & 20 & 4.0 & 614 & 74 & 12.0 \\
\hline $45-64$ & 460 & 16 & 3.5 & 707 & 92 & 13.0 \\
\hline
\end{tabular}

Table 6. Statistical Differences in Lifetime Prevalence of MDD by Age and Sex

\begin{tabular}{|c|c|c|c|c|c|c|c|c|c|c|}
\hline Age & Male \% & $\begin{array}{l}\text { Odds } \\
\text { Ratio }\end{array}$ & Cl $95 \%$ & $\begin{array}{c}\mathrm{X} 2 \\
\text { (1df) }\end{array}$ & $\mathbf{P}$ & $\begin{array}{c}\text { Female } \\
\%\end{array}$ & OR & Cl 95\% & $\begin{array}{c}\mathrm{X} 2 \\
\text { (1df) }\end{array}$ & $\mathbf{P}$ \\
\hline $18-24$ & 3.1 & $=$ & & $=$ & $=$ & 6.6 & $=$ & & $=$ & $=$ \\
\hline $25-44$ & 4.0 & 1.2 & $\begin{array}{c}0.44 \text { to } \\
3.2\end{array}$ & 0.10 & NS & 12.0 & 1.7 & 0.9 to 3.0 & 3.4 & NS \\
\hline $45-64$ & 3.5 & 1.1 & $\begin{array}{c}0.65 \text { to } \\
1.8\end{array}$ & 0.10 & NS & 13.0 & 1.9 & 1.6 to 3.5 & 4.8 & $\mathrm{P}<0.05$ \\
\hline$>64$ & 7.3 & 2.5 & $\begin{array}{c}0.9 \text { to } \\
6.8\end{array}$ & 3.13 & NS & 11.2 & 1.7 & 0.87 to 3.3 & 2.4 & NS \\
\hline
\end{tabular}

Table 7. Use of Antidepressant Drugs by Centre

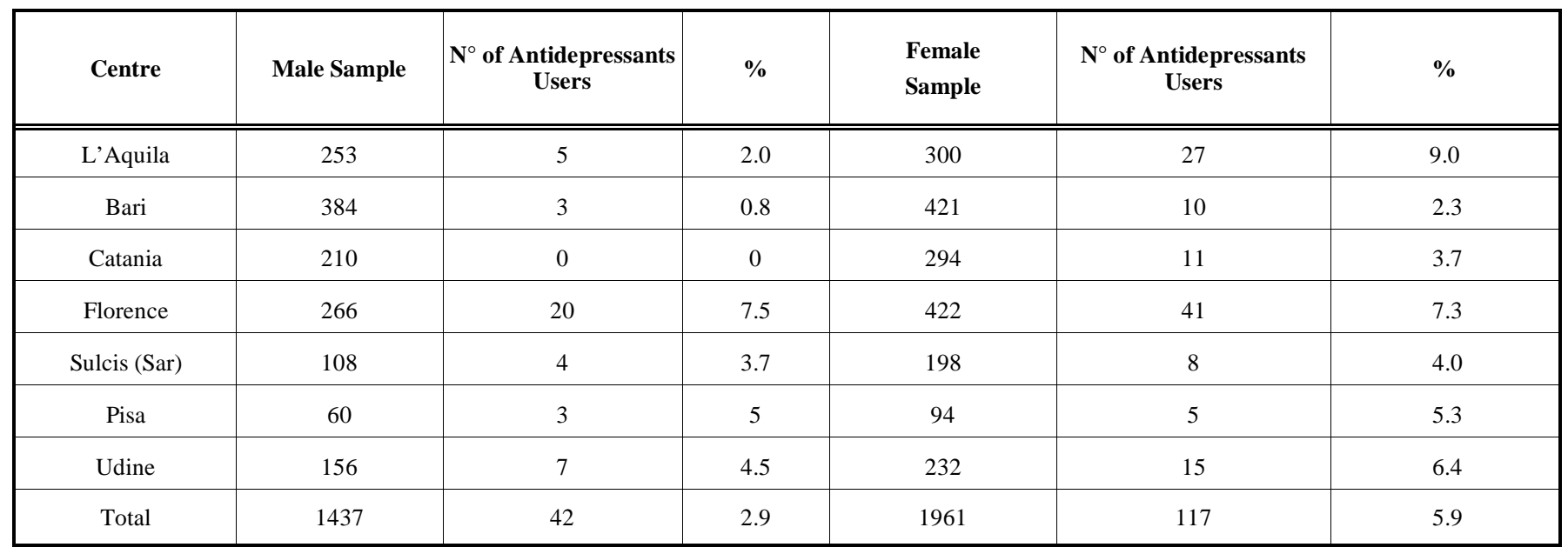

male the highest was L'Aquila $(9.0 \%)$ the lowest Bari $(2.3 \%)$.

Table $\mathbf{8}$ shows the community use of antidepressants in people with a lifelong diagnosis of MDD. We chose the lifetime prevalence because some people without symptoms who met the criteria for the diagnosis may have had an episode in the past and may have had the control of the symptoms by use of antidepressants. This may have been negative at the point of prevalence but may have been using antidepressants in a rationale way. As expected, due to the higher rate of depressive episodes, the use of antidepressants in depressed subjects is higher in females than in men $57 \%$ in contrast to $38 \%(O R=2.8,2$ with $1 d f=14.0 \quad P<0.0001)$. To be taken into account is if we consider the proportion of us- ers among the depressed, there is not statistical diference $(O R=2.1,2$ with $1 d f=3.5, P=0.60)$.

Comparison among centres didn't reach statistical significance in men ( 2 with $6 \mathrm{DF}$ and Bonferroni correction $2=1.9, \mathrm{P}=0.13$ ) but in females the difference was of statistical significance (2 with $6 \mathrm{DF}$ and Bonferroni correction $2=14.4, \mathrm{P}=0.025)$. In men, the centre with highest use in the depressed was Bari (100\%) and lowest was Florence $(7.5 \%)$, in females the highest were Pisa and Bari $(80 \%)$ the lowest was Udine $(33 \%)$.

More than $50 \%$ (63\% in females and $73 \%$ in males) of people were assuming antidepressant drugs without a lifetime diagnosis of MDD. 
Table 8. Use of Antidepressant Drugs by Centre in Subjects with a Lifelong MDD Diagnosis

\begin{tabular}{|c|c|c|c|c|c|c|}
\hline Centre & Male Sample & $\begin{array}{l}\mathbf{N}^{\circ} \text { of Antidepres- } \\
\text { sants Users }\end{array}$ & $\begin{array}{c}\% \\
\text { Of all Users }\end{array}$ & $\begin{array}{l}\text { Female } \\
\text { Sample }\end{array}$ & $\begin{array}{c}\mathbf{N}^{\circ} \text { of } \\
\text { Antidepressants Users }\end{array}$ & $\begin{array}{c}\% \\
\text { Of All Users }\end{array}$ \\
\hline L'Aquila & 253 & 2 & 40 & 300 & 15 & 55 \\
\hline Bari & 384 & 3 & 100 & 421 & 8 & 80 \\
\hline Catania & 210 & 0 & 100 & 294 & 5 & 45 \\
\hline Sulcis (Sar) & 108 & 2 & 50 & 198 & 4 & 50 \\
\hline Pisa & 60 & 0 & 100 & 94 & 4 & 80 \\
\hline Udine & 156 & 2 & 28 & 232 & 5 & 33 \\
\hline Total & 1437 & 16 & 38 & 1961 & 61 & 57 \\
\hline
\end{tabular}

Table 9. Use of Antidepressants by Age and Sex

\begin{tabular}{|c|c|c|c|c|c|c|}
\hline Age & Male Sample & $\begin{array}{c}\mathbf{N}^{\circ} \text { of Antidepres- } \\
\text { sants Users }\end{array}$ & $\boldsymbol{\%}$ & $\begin{array}{c}\text { Female } \\
\text { Sample }\end{array}$ & $\begin{array}{c}\mathbf{N}^{\circ} \text { of antidepres- } \\
\text { sants Users }\end{array}$ & 5 \\
\hline \hline $18-24$ & 192 & 3 & 1.6 & 241 & 26 & 2.3 \\
\hline $25-44$ & 499 & 13 & 2.6 & 614 & 58 & 4.2 \\
\hline $45-64$ & 460 & 12 & 2.6 & 707 & 28 & 7.2 \\
\hline$>64$ & 286 & 14 & 4.9 & 399 & 28 \\
\hline
\end{tabular}

Table 10. Statistical Differences in Use of Antidepressants Drugs by Age and Sex

\begin{tabular}{|c|c|c|c|c|c|c|c|c|c|c|}
\hline Age & Male \% & Odds Ratio & Cl 95\% & $\begin{array}{c}\text { X2 } \\
\text { (1df) }\end{array}$ & P & $\begin{array}{c}\text { Female } \\
\%\end{array}$ & OR & C1 95\% & $\begin{array}{c}\text { X2 } \\
\text { (1df) }\end{array}$ & $\begin{array}{c}\text { P } \\
=\end{array}$ \\
\hline \hline $18-24$ & 1.6 & $=$ & & $=$ & $=$ & 2.3 & $=$ & & $=$ \\
\hline $25-44$ & 2.6 & 1.7 & 0.2 to 13.6 & 0.3 & NS & 4.2 & 1.9 & 0.9 to 3.8 & 1.2 & NS \\
\hline $45-64$ & 2.6 & 1.7 & 0.2 to 13.6 & 0.3 & NS & 8.2 & 3.8 & 1.5 to 9.3 & 8.4 & P $=0.004$ \\
\hline$>64$ & 4.9 & 3.2 & 0.8 to 12.9 & 2.8 & NS & 7.4 & 4.8 & 2.0 to 11.4 & 10.8 & P $<0.001$ \\
\hline
\end{tabular}

The use of antidepressants by age and sex is reported in Table 9.

Table $\mathbf{1 0}$ shows the statistical differences in use of antidepressant drugs per age and sex. The use of antidepressants increased by age and females older than 45 years old had antidepressant use higher than those in the younger age groups.

\section{DISCUSSION}

The MDD prevalence identified in the community by means of a "clinical method", using clinicians as interviewers and a semi-structured diagnostic tool, was quite lower than the prevalence identified in the same cultural setting in studies using lay interviewers and structured tools. In fact, the Esemed project found a $10 \%$ lifetime rate of MDD in Italy [11] in a representative nationwide sample. We must also point out tha the prevalence of MDD in Italy was the lowest of all six European countries participating in the project. In this perspective, our study seems to confirm the low rate of mood disorders shown in most Italian community surveys [12].

Compared with the figures reported by the studies that used lay interviewers, the use of antidepressant drugs found in this study was decidedly higher. For example, the Esemed study reported use of antidepressant drugs in $1 \%$ of the community [11]. The results of this study demonstrate tallies well within the data regarding the sales of antidepressants in Italy: the Report on Mental Health in Europe shows that direct expenditure for $\mathrm{AD}$ incremented around $25 \%$ in Italy from 2000-2002. A rate which is the highest among the topranking European markets [1].

Data produced by the Italian Health Ministry shows that expenditure augmentation has paralleled that of the prescriptions [13].

The rate of antidepressant use in this study is similar of those found by a Sardinian survey in 2003, in which the rate of adults in the general population who took antidepressants was $4.2 \%$ [3]. 
A number of population surveys have shown that the AD usage increase is associated with a better response to the needs of patients with a diagnosis of depression [3]. However, the appropriateness of $\mathrm{AD}$ prescription is still open to debate.

An Italian survey [5] found that only about $21 \%$ of those who may benefit from an $\mathrm{AD}$, actually receive such drugs. This value was even lower than that (39\%) found by Bellantuono et al. [14] in another Italian investigation. Taken together, the low proportion of coverage in both studies strongly indicates that in Italy most patients affected by a clinically relevant depressive state do not receive antidepressant drugs. For over a decade (1991 to 2002), in the Italian region Sardinia, the number of individuals with a defined diagnosis of depression, who were taking $\mathrm{AD}$, increased from $8 \%$ to $40 \%$.

In this study, $38 \%$ of males and $57 \%$ of females had a lifetime diagnosis of MDD and were taking antidepressant drugs. Cross comparison of the present data with findings of other national and international studies is of particular interest, although the results of this comparison should be considered with caution in view of the different sampling techniques applied and type of instruments used.

If the field is restricted to recent studies performed using tools based on the CIDI interview [15], an important finding which emerges is that the proportion of subjects with a diagnosis of depressive episode who were on antidepressants is markedly higher than the proportion reported in similar studies from Italy and North America; in fact a Canadian study reported that $14.9 \%$ of depressed subjects "in the community" were treated with antidepressants whilst the renowned USA National Comorbidity Survey reported a figure of only $7.3 \%$ [16]. In part, this positive result may be likely determined by the possibility of free access health services operated by the National Health System in Italy. Even with this said, the Esemed study in Italy indicates that only $10 \%$ of people with diagnosed MDD in the last 12 months have been taking antidepressant drugs (http://www.iss.it/pres/prim/ cont.php?id=854\&tipo=6\&lang=1). Thus it is correct to affirm that the correspondence between lifetime MDD diagnosis and use of antidepressant drugs in the present study was closer than reported by the literature that used non clinical interviewers.

A source of difference may be the different measure of MDD frequencies used in the studies for assessing the association between antidepressant and MDD diagnosis. Our survey used lifetime prevalence due to the fact that several evidences show the efficacy in the long term treatment (three or more years) of antidepressants for MDD [17], thus a long term assumption may be evidence based.

In every way, also in the light of a probably better condition than other settings, it is worth noting that more than $50 \%$ of people are assuming antidepressant drugs without a lifetime diagnosis of MDD. This confirms the broad use of $\mathrm{AD}$ for indications other than depressive disorders.

This study was supported by a grant of AIFA (Agenzia Italiana del Farmaco) Number FARM54S73S, approved in 2005.

\section{REFERENCES}

[1] European Commission, editor. The State of Mental Health in the European Union. Luxemburg: Directorate General for Health and Consumer Protection; 2004. Available from: http://ec.europa.eu/health/ph_projects/2001/monitoring/fp_monitori ng_2001_frep_06_en.pdf

[2] Carta MG, Hardoy MC, Cadeddu M, Mura G, Floris AL, Carpiniello B. Psychotropic drug use in a sample of general population in the Sardinia region. Epidemiol Psichiatr Soc 2003; 12: 287-92.

[3] World Health Organisation. The ICD-10 classification of mental and behavioral disorders: Clinical description and diagnostic guidelines (ICD-10). Geneva: WHO; 1992.

[4] American Psychiatric Association. Diagnostic Statistical Manual (DSM) IV-TR. Washington DC: APA; 1994.

[5] Balestrieri M, Carta MG, Leonetti S, Sebastiani G, Starace F, Bellantuono C. Recognition of depression and appropriateness of antidepressant treatment in Italian primary care. Soc Psychiatry Psychiatr Epidemiol 2004; 39: 171-6.

[6] Paykel ES, Freeling P, Hollyman JA. Are tricyclic antidepressants useful for mild depression? A placebo controlled trial. Pharmacopsychiatry 1988; 21(1): 15-8.

[7] Rocca P, Calvarese P, Faggiano F, et al. Citalopram versus sertraline in late-life nonmajor clinically significant depression: a 1year follow-up clinical trial. J Clin Psychiatry 2005; 66(3): 360-9.

[8] Bower P, Rowland N, Hardy R. The clinical effectiveness of counselling in primary care: a systematic review and meta-analysis. Psychol Med 2003; 33(2): 203-15.

[9] First M, Spitzer R, Gibbon M, Williams J. Structured clinical interview for DSM-IV axis I disorders, research version, non-patient edition (SCID-I/ NP). New York: Biometrics Research, New York State Psychiatric Institute; 1997.

[10] Carta MG, Lecca ME, Hardoy MC. "The use of drugs for mood disorders in Italy, Progetto AIFA: FARM54S73S. Validità comparativa dell'intervista A.N.T.A.S Advanced Neuropsychiatric Tools and Assessment Schedule". In: Convegno ricerca indipendente sul farmaco. Roma: AIFA; 2008.

[11] De Girolamo G, Polidori G, Morosini P, et al. Prevalence of common mental disorders in Italy: results from the European Study of the Epidemiology of Mental Disorders (Esemed). Soc Psychiatry Psychiatr Epidemiol 2006; 41(11): 853-61.

[12] Gigantesco A, Palumbo G, Mirabella F, Pettinelli M, Morosini P. Prevalence of psychiatric disorders in an Italian town: low prevalence confirmed with two different interviews. Psychother Psychosom 2006; 75(3): 170-6.

[13] Carta MG, Kovess V, Hardoy MC, et al. Psychosocial wellbeing and psychiatric care in the European Communities: analysis. Soc Psychiatry Psychiatr Epidemiol 2004; 39(11): 883-92.

[14] Bellantuono C, Rizzo R, Mazzi M, Goldberg D, Tansella M. The identification of depression and the coverage of antidepressant drug prescriptions in Italian general practice. J Affect Disord 2002; 72: 53-59.

[15] Robins LN, Wing J, Wittchen HU, Helzer JE. The Composite International Diagnostic Interview. An epidemiologic instrument and in different cultures. Arch Gen Psychiatry 1988; 45: 1069-1077.

[16] Katz SJ, Kessler RC, Lin E. Medical management of Depression in the United States and Ontario. J Gen Intern Med 1998; 13: 77-85.

[17] Shelton RC. Long-term management of depression: tips for adjusting the treatment plan as the patient's needs change. J Clin Psychiatry 2009; 70 (Suppl 6): 32-7.

Received: November 09, $2009 \quad$ Revised: March 03, $2010 \quad$ Accepted: March 03, 2010

(C) Carta et al.; Licensee Bentham Open.

This is an open access article licensed under the terms of the Creative Commons Attribution Non-Commercial License (http://creativecommons.org/licenses/by-nc/3.0/) which permits unrestricted, non-commercial use, distribution and reproduction in any medium, provided the work is properly cited. 